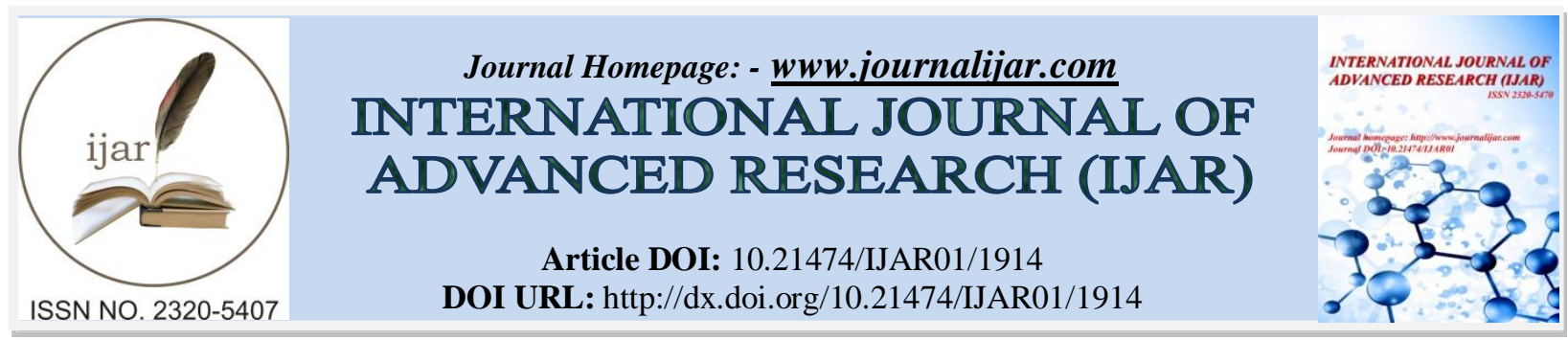

RESEARCH ARTICLE

\title{
A COMPARATIVE STUDY OF DIFFERENT MODALITIES OF DRESSING IN CHRONIC WOUNDS.
}

Ashok Swaminathan Govindarajan ${ }^{1 *}$, Shabnam Fathima ${ }^{2}$ and Subramanian.C.S ${ }^{2}$ and Sivaraj ${ }^{3}$.

1. Department of Plastic Surgery, Rajah Muthiah Medical College, Annamalai Nagar, Chidambaram. Tamil Nadu, India.

2. Department of Surgery, Rajah Muthiah Medical College, Annamalai Nagar, Chidambaram.Tamil Nadu, India.

3. Department of Pharmacology, AVMC, puducherry,India.

\section{Manuscript Info}

............................

Manuscript History

Received: 12 August 2016

Final Accepted: 13 September 2016

Published: October 2016

\section{Abstract}

Copy Right, IJAR, 2016,. All rights reserved.

\section{Introduction:-}

Chronic wound is defined as an insult or injury that has failed to proceed through an orderly and timely process to produce anatomic and functional integrity, or proceeded through the repair process without establishing a sustained anatomic and functional result ${ }^{1}$. The wounds that have failed to heal for over a period of 4 weeks are regarded as chronic wounds.

The prevalence of chronic wounds in India is 4.48 per 1000 of the population ${ }^{2}$. The annual cost for management of chronic wounds in USA alone is greater than $\$ 20$ billion $^{3,4}$.

Negative pressure wound therapy (NPWT) in its most current form has been used steadily to heal complex wounds since its introduction by Fleischmann et $\mathrm{al}^{5}$. While this technology seems relatively recent to modern medicine, its roots go back to the earliest civilizations. In this study, it is compared with the other commonly available modalities of dressing such as moist dressing, honey based dressing, phenytoin dressing and topically applied growth factors.

There has been a renaissance in recent times in the use of honey, an ancient and traditional wound dressing, for the treatment of wounds, burns, and skin ulcers. As a dressing on wounds, honey provides a moist healing environment, rapidly clears infection, deodorizes, and reduces inflammation, edema, and exudation. Also, it increases the rate of healing by stimulation of angiogenesis, granulation, and epithelialization. ${ }^{6}$

Diphenyl hydantoin sodium (phenytoin) is an effective anti-epileptic medication. Its capacity to accelerate ulcer healing was reported more than 40 years ago ${ }^{7}$. Possible mechanisms of action of phenytoin cream on wound healing are as follows:

1. Decrease in serum corticosteroid

2. Acceleration of assembly and presence of collagen and fibrin in the ulcer area, and stimulation of alkaline phosphatase secretion $^{8}$

C orresponding Author:- Ashok Swaminathan Govindarajan. Address: Department of Plastic Surgery, Rajah Muthiah Medical College, Annamalai Nagar, Chidambaram. Tamil Nadu, India. 
Epidermal regeneration depends on mitosis and migration of keratinocytes. Epidermal growth factor is known to stimulate growth of keratinocytes in vitro, thus it might be expected to promote wound healing. Though cost is a deterring factor, many studies have proved its wound healing properties ${ }^{9}$

\section{Inclusion criteria:-}

- Age greater than 12 years.

- Clean contaminated wounds.

- Chronic wounds.

- Diabetic ulcers.

- Venous ulcers.

- Post traumatic ulcers.

- Post animal/insect bite ulcers.

\section{Exclusion criteria:-}

- Age less than 12 years

- Wounds associated with multiple compound fractures, untreated osteomyelitis

- Mangled foot

- Malignancy and peripheral vascular disease.

- Actively bleeding wound

- Burns

In this study 50 cases of chronic non-healing ulcers were studied under five groups in the department of surgery at Rajah Muthiah Medical College from July 2014 to July 2016. It is a prospective randomized control study.

Patients were assigned randomly to the five groups by lot system. Group I patients were subjected to Negative Pressure Wound Therapy. Patients belonging to groups II, III, IV and V were subjected to moist dressing, phenytoin based dressing, honey based dressing and topical growth factor based dressing.

All patients included in the study where treated by the sensitive antibiotics according to wound culture and sensitivity. Nutrition assessment was done and necessary treatment was given. The co morbid conditions were also addressed. Regular surgical debridement of necrotic debris was done. Immobilization of the limb was done in only the cases which required so. Clinical parameters assessed before dressing change were wound size, pain and discharge from wounds.

The wounds of patients belonging to group I was cleaned, then wounds was covered with sterilized foam, then ryles tube or any tube with multiple tube at the end to deliver the negative pressure was placed and secured with a transparent plastic covering to maintain a closed envoirment and connected to suction unit. The negative pressure was delivered by a wall mounted central suction apparatus as it was cost effective and easily available. The pressure was maintained as $120 \mathrm{mmHg}$ for 30 minutes for every 3 hour. The dressing was opened after 5 days of such therapy. The wound was assessed for granulation tissue, size of wound and discharge.

The group II was subjected to moist dressing with sterilized gauze and pad using normal saline. Then the wounds were closed firmly with clean linen gauze. The dressing was changed twice daily.

The group III patients' wounds were covered with honey sand witched between layers of gauze. The gauze was used as contact layer in the dressing. Then they were secured with clean linen gauze. The dressing was changed daily once.

The group IV patients' wounds were subjected to crushed phenytoin powder in normal saline as contact layer then gauze was used to secure the dressing. It was also changed once daily.

The wound of patients in group $\mathrm{V}$ were covered with topical growth factor ointment then dressed with gauze and pads and secured with linen gauze roll which was changed twice daily. 
Data was collected in the form of a proforma which included in addition to the epidemiological data and clinical data, wound area measurements on $1^{\text {st }} 5^{\text {th }}, 10$ th and $15^{\text {th }}$ day.

\section{Wound area measurement:-}

The wounds were photographed on day 1,510 and $15^{\text {th }}$ day using a digital camera at a distance of $40 \mathrm{cms}$ without using a flash. The wound was photographed along with a reference object and respective wound areas calculated.

\section{Observations and Results}

The mean age of the study population was around 54.4 years. The male, female ratios in all the groups were in the ratio of 6:4.The majority of the patients included in the study were belonging to diabetic foot category. They comprised about $56 \%$ of the patient population. Next post traumatic ulcer and venous ulcers topped the list with 14 $\%$ each. About $6 \%$ belonged to decubitus ulcer category. Rest belonged to post snake bite.

The mean area of the ulcers in the case group was higher when compared to the other groups but this difference is not statistically significant. The ulcers in the NPWT group show a faster healing rate but it is not statistically significant .The rates of reduction in area within in the groups were highly significant.

Mean area of the ulcers in each group (sq mm):-

\begin{tabular}{|c|c|c|c|c|c|}
\hline DAY & NPWT & MOIST & PHENYTOIN & HONEY & TOPICAL GROWTH FACTOR \\
\hline 0 & 5746.2 & 4350.3 & 4150.5 & 2582.8 & 4209.4 \\
\hline 5 & 3432.1 & 2503.7 & 3054.9 & 1661.9 & 3329.4 \\
\hline 10 & 1762.7 & 1556.1 & 2270.3 & 1157 & 2652 \\
\hline 15 & 827.9 & 846.2 & 1635 & 573.4 & 1964.4 \\
\hline
\end{tabular}

Rate of reduction of ulcer as percentage of its initial area:-

\begin{tabular}{|c|c|c|c|c|c|}
\hline DAY & NPWT & MOIST & PHENYTOIN & HONEY & $\begin{array}{c}\text { TOPICAL GROWTH } \\
\text { FACTOR }\end{array}$ \\
\hline 0 & 100 & 100 & 100 & 100 & 100 \\
\hline 5 & 61.855 & 62.16 & 70.09 & 69.85 & 74.12 \\
\hline 10 & 35.84 & 37.70 & 47.94 & 48.86 & 51.64 \\
\hline 15 & 15.11 & 21.65 & 33.44 & 25.57 & 32.89 \\
\hline
\end{tabular}

The negative pressure wound therapy on comparison with the moist dressing showed greater reduction in area when the initial wound area is compared to the subsequent area measurements expressed as the percentage of the initial. But the values were not statistically significant. But healing and wound area reduction did occur at faster in the negative pressure wound therapy category.

Npwt vs moist dressing (sq mm).

\begin{tabular}{|c|c|c|c|c|}
\hline Area & $\begin{array}{c}\text { Number of } \\
\text { Patients }\end{array}$ & Day 5 & Day 10 & Day 15 \\
\hline NPWT & 10 & $61.85 \pm 11.86$ & $35.84 \pm 8.35$ & $15.11 \pm 7.89$ \\
\hline Moist & 10 & $62.16 \pm 9.25$ & $37.70 \pm 12.50$ & $21.65 \pm 8.4$ \\
\hline \multicolumn{2}{|c|}{ P value } & 0.458 & 0.822 & 0.712 \\
\hline
\end{tabular}




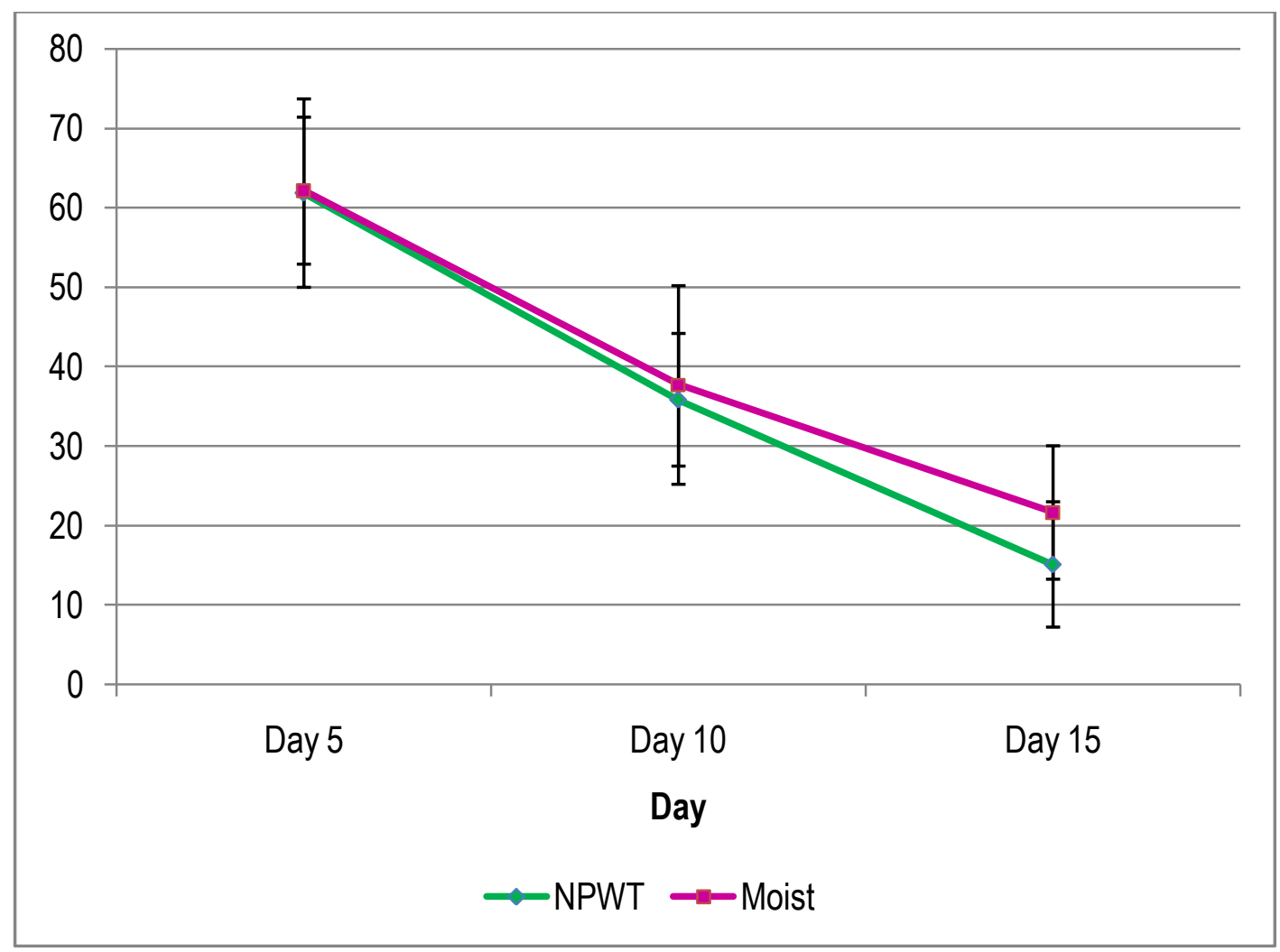

The negative pressure wound therapy on comparison with the phenytoin dressing showed greater reduction in area. The values were not statistically significant on day 5 comparison $\quad(\mathrm{p}<0.101)$ but the values were significant on day 10 and day 15 ( $\mathrm{p}<0.021$ and $\mathrm{p}<0.036)$.

Npwt vs phenytoin dressing(sq mm).

\begin{tabular}{|c|c|c|c|c|}
\hline Area & $\begin{array}{c}\text { Number of } \\
\text { Patients }\end{array}$ & Day 5 & Day 10 & Day 15 \\
\hline NPWT & 10 & $61.85 \pm 11.86$ & $35.84 \pm 8.35$ & $15.11 \pm 7.89$ \\
\hline Phenytoin & 10 & $70.09 \pm 17.18$ & $47.94 \pm 22.76$ & $33.44 \pm 21.41$ \\
\hline \multicolumn{2}{|c|}{ P value } & 0.101 & 0.021 & 0.036 \\
\hline
\end{tabular}




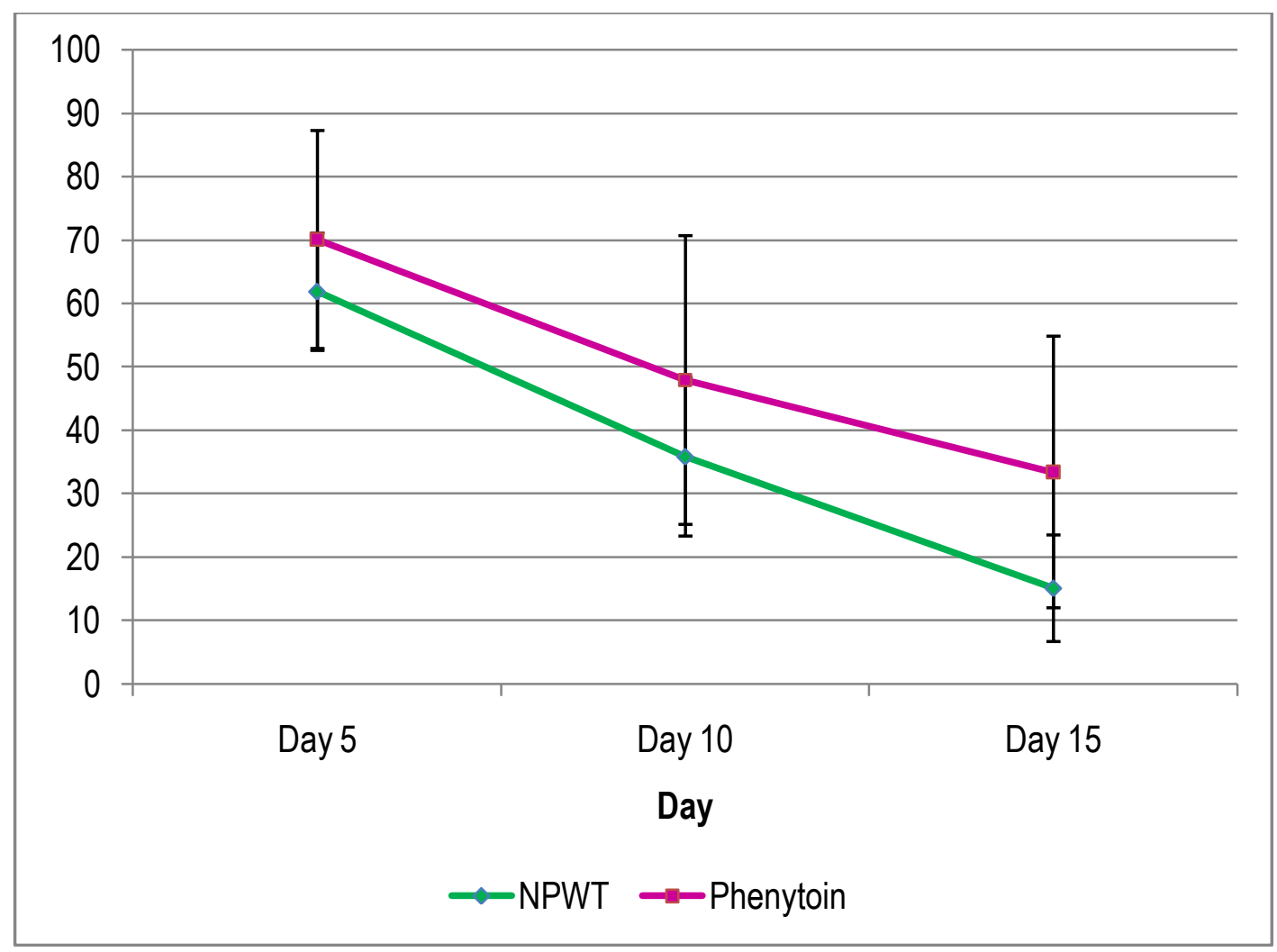

On comparison with the honey dressing, the values were not statistically significant on day 5 comparison $(\mathrm{p}<0.521)$ but the values were significant on day 10 and day $15(\mathrm{p}<0.022$ and $\mathrm{p}<0.011)$.

NPWT VS HONEY DRESSING(SQ MM).

\begin{tabular}{|c|c|c|c|c|}
\hline AREA & $\begin{array}{c}\text { NUMBER OF } \\
\text { PATIENTS }\end{array}$ & DAY 5 & DAY 10 & DAY 15 \\
\hline NPWT & 10 & $61.85 \pm 11.86$ & $35.84 \pm 8.35$ & $15.11 \pm 7.89$ \\
\hline Honey & 10 & $69.85 \pm 12.38$ & $48.86 \pm 16.53$ & $25.57 \pm 16.71$ \\
\hline \multicolumn{2}{|c|}{ P value } & 0.521 & 0.022 & 0.011 \\
\hline
\end{tabular}




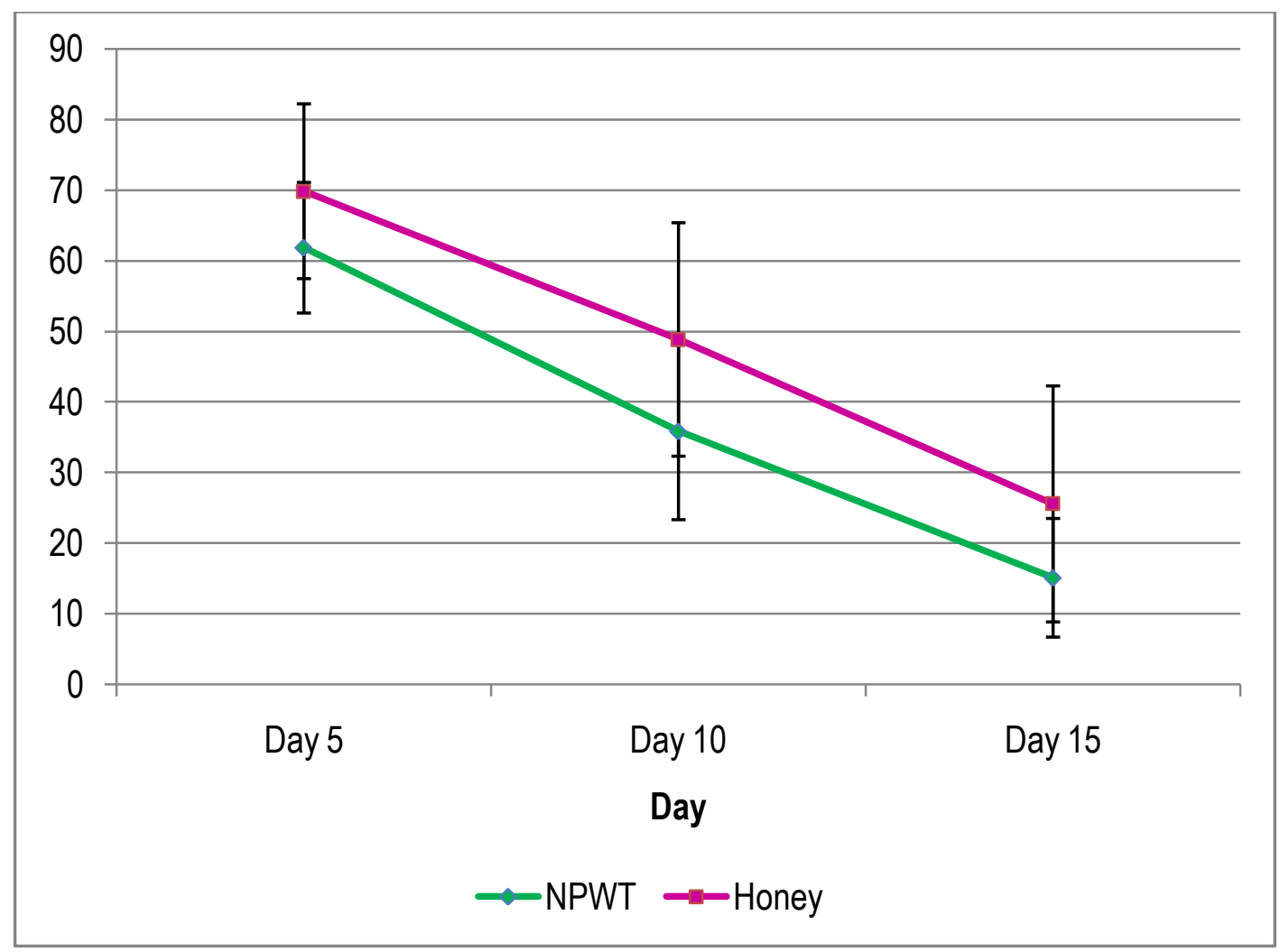

On comparison with the topical growth factor dressing, the values were not statistically significant on day 5 and day $10(\mathrm{p}<0.642$ and $\mathrm{p}<0.128)$ but the values were significant on day $15(\mathrm{p}<0.013)$.

NPWT VS TOPICAL GROWTH FACTOR DRESSING(SQ MM)

\begin{tabular}{|c|c|c|c|c|}
\hline AREA & $\begin{array}{c}\text { NUMBER OF } \\
\text { PATIENTS }\end{array}$ & DAY 5 & DAY 10 & DAY 15 \\
\hline NPWT & 10 & $61.85 \pm 11.86$ & $35.84 \pm 8.35$ & $15.11 \pm 7.89$ \\
\hline $\begin{array}{c}\text { Topical } \\
\text { growth factor }\end{array}$ & 10 & $74.12 \pm 13.21$ & $51.64 \pm 14.94$ & $32.89 \pm 17.66$ \\
\hline \multicolumn{2}{|c|}{ P value } & 0.642 & 0.128 & 0.013 \\
\hline
\end{tabular}




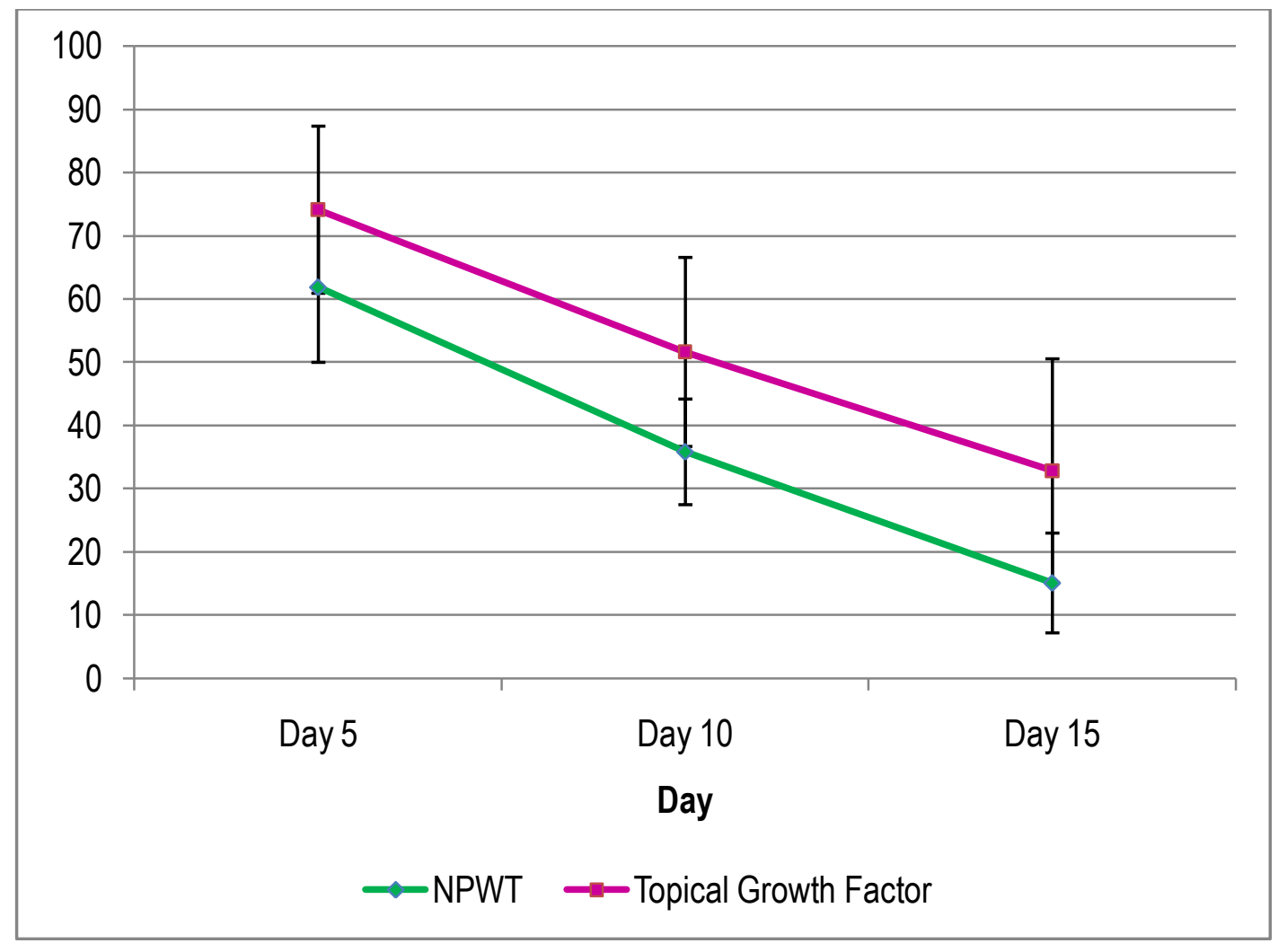

\section{Discussion:-}

The chronic wounds included in the study had diverse etiology but the diabetic wounds formed the major component of each group. Both the groups had comparable age and sex distribution. Among all the groups, the comparison between the negative pressure wound therapy and honey and the same with topical growth factor showed more significant values statistically. The comparison between the negative pressure wound therapy and moist dressing did not show statistically significant values but healing is better in the former group. The results were analyzed by unpaired students $\mathrm{T}$ test. As negative pressure wound therapy resulted in better wound healing at a faster rate, it was much cost effective in comparison to the rest. The hospital stay was also comparatively lesser in negative pressure wound therapy group. The patients were compliant and there was no attrition in the study. The patients complained of pain, soddening of surrounding skin of the wound and restriction of mobility during the negative pressure wound therapy as disadvantages.

The mean area of the wounds measured on day 0 of study in the negative pressure wound therapy group was 5746.2 sq $\mathrm{mm}$. which was greater compared to the other groups. This is probably due to a bias in allotting bigger, hence more difficult ulcers to the NPWT group. In spite of the apparent difference in the size of the wounds the differences were not statistically significant. In our study the wounds in the moist dressing category had a mean area of $4350.3 \mathrm{sq} \mathrm{mm}$ at the start of the study, then $2503.7 \mathrm{sq} \mathrm{mm}$ on day 5 and $1556.1 \mathrm{sq} \mathrm{mm}$ on day 10 and $846.2 \mathrm{sq} \mathrm{mm}$ on day 15. These results when compared to the NPWT revealed that the wounds that were subjected to NPWT did heal faster than the ulcers in the moist dressing category but the differences were not statistically significant.

Since the initial areas of the wounds are not uniform the comparison of these values could be misleading, hence serial measurements of the wounds were represented as percentage of the original area of each ulcer. All the ulcers had a value of $100 \%$ on day 0 and the subsequent shrinkage in size of the wounds were represented as a fraction of the original value. By this standardization the wounds in the negative pressure wound therapy category had healed faster and this was statistically significant in comparison between the NPWT and phenytoin, honey and topical growth factor based dressings ( $\mathrm{p}<0.036, \mathrm{p}<0.011$ and $\mathrm{p}<0.013$ ). This indicates to a factor in the NPWT group which has at least accelerated the rate of re epithelialization and wound contraction but this has to be substantiated by further studies. A prospective randomized evaluation of negative pressure wound dressing for diabetic foot wounds by Mark T. Eginton et all ${ }^{12}$ published in annals of vascular surgery compared the rate of wound healing with 
the Vacuum Assisted Closure device ${ }^{\mathrm{TM}}$ (VAC) to conventional moist dressings in the treatment of large diabetic foot wounds ${ }^{10}$. VAC dressings decreased the wound volume and depth significantly more than moist gauze dressings (59\% vs. $0 \%$ and $49 \%$ vs. $8 \%$, respectively).

In 1939 Kimball first observed that gingival hyperplasia occurred in some patients treated with phenytoin ${ }^{13}$. The earliest clinical study of phenytoin in cutaneous wound healing used oral phenytoin sodium to treat venous stasis ulcers in 28 patients in a double-blind, placebo-controlled trial. At the end of 13 weeks, the mean-wound area in the treatment group decreased by $0.65 \mathrm{~cm}^{2}$, whereas in the control group, the lesion area increased by $7.7 \mathrm{~cm}^{2}$. A number of clinical studies indicate that phenytoin decreases the bacterial load of wounds. Local pain relief has also been observed with topical phenytoin therapy, which can be explained by its membrane-stabilizing action ${ }^{11}$. Facilitation of nerve regeneration has also been reported with phenytoin ${ }^{12}$.

In this study wounds that were subjected to phenytoin dressing showed reduction to $70.09 \%$ of wound area on day 5 , then to $47.94 \%$ of initial wound area on day 10 and finally the wound shrunk to $33.44 \%$ of initial area on day 15 . But the wounds subjected to negative pressure wound therapy healed at a faster with statistically significant values ( $\mathrm{p}<0.021$ on day 10 and $\mathrm{p}<0.036$ on day 15$)$.

The use of honey in treating wounds has been long known, with such use being recorded in 4,000 year old Sumerian clay tablets $^{13}$. Recent international medical literature record honey as being effective as a dressing for wounds, burns and skin ulcers. Recorded observations include that inflammation, swelling and pain were quickly reduced; that sloughing of necrotic tissue occurs without the need for debridement, and that growth of tissues to repair the wound is stimulated. As a consequence, healing occurs rapidly.

In comparison with negative pressure wound therapy the healing with honey based dressing was at slower rate than the negative pressure wound therapy which was statistically significant $(\mathrm{p}<0.022$ on day 10 and $\mathrm{p}<0.011$ on day $15)$.

Steed et al in their study on the efficacy of topical growth factor on lower extremity ulcers on 922 patients demonstrated that patients treated with PDGF at $100 \mu \mathrm{g} / \mathrm{g}$ had a significant increase in complete healing compared with patients given placebo (50 percent versus 36 percent, $\quad p<0.007)^{14}$. PDGF also decreased the time to complete healing by 30 percent ( 14 weeks versus 20 weeks, $p=0.01$ ). Adverse events were similar in both treatment groups, as were recurrent ulcer rates. Though wound healing is promoted by topical growth factor based dressings , the negative pressure based therapy showed significantly better healing on day $15(\mathrm{p}<0.013)$. Thus on long term the negative pressure based therapy showed better results than topical growth factor based therapy.

It was observed that though wounds healed faster when subjected to negative pressure wound therapy, such an effect could be demonstrated statistically only after day 10 .

\section{Limitations of the study:-}

The most important limitation of the study is its sample size. A randomized control study with much larger population may help to further substantiate the findings or reveal variations. The cost burden of the patients can be influenced by many factors other than the cost of dressing materials alone. The negative pressure therapy in this study was provided with lesser cost with easily available sources such as wall mounted central suction, Ryle's tube with extra holes, food grade plastic sheets for wrapping the wound and sterilized foam. The overall cost of the dressings was lesser as it was done only once in five days whereas in other groups the dressing were done daily or twice daily and thus was higher in other groups..

The assessment of end results such as graft uptake, recurrence of the ulcer, residual raw area and pain were not included in the study, which if included might have given a much better analysis of the efficacy of negative pressure wound therapy as compared to other modalities of dressing.

\section{Conclusion:-}

- The overall cost of dressing was lesser in the negative pressure wound therapy category with lesser hospital stay.

- No intolerable side effects in this group, negative pressure wound therapy can be considered as a superior option in the management of chronic wounds. 
- NPWT increases wound healing probably by increasing the rate of re epithelialization and wound contraction as observed by the faster reduction in the wound area. Larger and in depth study are required to investigate this effect of the therapy.

- $\quad$ NPWT is a safe and effective adjuvant modality of treatment for chronic wounds.

\section{References:-}

1. Lazarus, Gerald S., et al. "Definitions and guidelines for assessment of wounds and evaluation of healing." Wound Repair and Regeneration 2.3 (1994): 165-170.

2. Gupta, N., et al. "An Indian community-based epidemiological study of wounds." Journal of wound care 13.8 (2004): 323-325.

3. Boulton, Andrew JM, et al. "The global burden of diabetic foot disease." The Lancet 366.9498 (2005): 17191724.

4. Mody, Gita N., et al. "A blinded, prospective, randomized controlled trial of topical negative pressure wound closure in India." Ostomy/wound management 54.12 (2008): 36-46.

5. Fleischmann W, Strecker W, Bombelli M, Kinzl L. Vacuum sealing as treatment of soft tissue damage in open fractures. Unfallchirurg 1993;96:488-92.

6. Montenegro G, Mejias E. Biological applications of honeys produced by Apis mellifera. Biol Res. 2013;46(4):341-345.

7. Shapiro $M$ : Acceleration of gingival woundhealing in nonepileptic patients recieving diphenyl hydantoin sodium. Exp Med Surg 1958, 16: 41-53.

8. Kelin EE, Gorling RJ: Healing qualities of an epilepsy drug. Dental Prog 1961, 1: 126-9.

9. Brown, Gregory L., et al. "Enhancement of epidermal regeneration by biosynthetic epidermal growth factor." The Journal of experimental medicine 163.5 (1986): 1319-1324.

10. Eginton, Mark T., et al. "A prospective randomized evaluation of negative-pressure wound dressings for diabetic foot wounds." Annals of vascular surgery 17.6 (2003): 645-649.

11. Kimball, O. P. "The treatment of epilepsy with sodium diphenyl hydantoinate." Journal of the American Medical Association 112.13 (1939): 1244-1245.

12. McQuay, Henry, et al. "Anticonvulsant drugs for management of pain: a systematic review." Bmj 311.7012 (1995): 1047-1052.

13. Lee, David S., Sammy Sinno, and Amor Khachemoune. "Honey and wound healing." American journal of clinical dermatology 12.3 (2011): 181-190.

14. Steed, David L. "Clinical evaluation of recombinant human platelet-derived growth factor for the treatment of lower extremity ulcers." Plastic and reconstructive surgery 117.7S (2006): 143S-149S. 